\title{
Recreational Areas as a Basis of the Municipal and Urban Territories' Ecological Framework
}

\author{
Eugenia Ketova ${ }^{1,{ }^{*}}$ and Julia Lesotova ${ }^{1}$ \\ ${ }^{1}$ Novosibirsk State University of Architecture and Civil Engineering (SIBSTRIN), Leningradskaya \\ str., 113, Novosibirsk, 630089, Russia
}

\begin{abstract}
Nowadays, population migration from small settlements to large ones and big cities is typical; as a result, it becomes urgent to study the urban environment as the main sphere of human habitation. The problem of the environment quality becomes more and more relevant every year. Rapid growth of cities, industrial construction, development of highways networks and vehicles become the root cause of the harmful effects on the atmosphere. Therefore, environmental pollution is a worldwide environmental problem for cities. The goal of the work is to determine the importance of conservation, revival and design of recreational zones in a city body. The degradation of the function and the change in the demand structure for territory use comes with the appearance of new needs for the society, while the new activity comprehension and development of the already existing object becomes of little interest. The problem of maintaining ecological balance of large cities appeared in the middle of the XX century, in particular, it was connected with resource saving, air pollution through industrial enterprises emissions and vehicles into the atmosphere, in this connection, the preservation and revival of recreational areas in structure of cities
\end{abstract}

\section{Introduction}

A significant link in the urban environment and a tool for improving qualities of cities urban planning with an unfavorable ecological situation is the presence of recreational areas. The primary cause of air pollution in the cities is enterprises of industry, energy, as well as transport fuels. Natural complexes and recreational resources provide protection of public health, directly affecting the preservation and treating of human health, its psychological, emotional and physical condition.

The article deals with the "recreational territory" concept with reference to the Land Code of the Russian Federation (as amended on July 3, 2016) (edition effective January 1, 2017). In this regard, the presence of recreational areas in Novosibirsk structure was established. The issue of their importance in the formation of the city's structure and its ecological framework was fully developed in "Formation of the ecological framework as a principle of sustainable development of the urban environment" work (A. Kataeva). The possibility and necessity of an integrated approach applying to a city formation as a whole

* Corresponding author: $\underline{\operatorname{args} @ \text { sibstrin.ru }}$ 
is considered, referring both to the natural, anthropogenic and social factors affecting the integrity and safety of the environment. The territory development and a city skeleton are always closely connected with the "environmentally friendly economy", i.e. correlation of environmental laws with economic ones. This issue is considered Korobko V.I. training manual.

The sustainable development problem of territories with environmental indicators and the effectiveness of their use are taken into account, in combination with the main functions and purposes of lands relation, giving them different socioeconomic status, and, if necessary, adjustments are taken into account in Narbut O.N. article.

Human society has a direct impact on the natural framework. According to the Treyvish A.I. theory, industrial centers, large and small cities, transport infrastructure create a demoeconomic framework, which functioning inevitably has a negative impact on the natural environment, introducing a significant imbalance. Negative factors of influence on the environment are similar and relevant for a number of the largest cities in Siberia, including Novosibirsk, such as emissions of industrial pollutants into the atmosphere, urban and transport infrastructure.

\section{Materials and Methods}

According to the data (April 2017) of the Federal Agency for Hydrometeorology and Environmental Monitoring ("West Siberian "), it was found that Novosibirsk has a higher level of atmospheric pollution. But there is also a high level of pollution in urban industrial areas. Serious impact on public health and the environment is provided by urban vehicles acoustical and air -chemical pollution of roadside areas, and industrial enterprises (according to Russian consumer supervision, the share of people's complaints about noise is over $40 \%$, and over 10 million people are exposed to excess sound level in Russia). It should be noted that with the help of innovative technological lines and a change in production structure, the bulk of industry can function in the structure of cities, as there is a tendency to remove plants and factories out of cities.

Under the transport and industrial impact of pollution, by the gardening areas reducing due to the building industry development, climatic features of the region change, spontaneously formed recreation townspeople areas, there is a degradation, directly, of the ecological framework (greenery, coastal territories and water bodies), and in the suburban areas. As a study result of "ecological framework" concept in documents and scientific publications it is established that the ecological framework is a system of ecologically interrelated natural areas characterized by two signs:

1) ability to maintain ecological balance in the region;

2) protection by nature measures, corresponding to the stresses on nature [2].

Achievement of ecological balance and nature protection is achieved due to the step-bystep ecological framework organization. The ecological framework consists of three types of territories that are interrelated and has a specific function (Table 1).

Table 1. Structure of the ecological framework

\begin{tabular}{|c|c|c|}
\hline \multicolumn{3}{|c|}{ Environmental framework } \\
\hline Key territories & Transit areas & Buffer areas \\
\hline $\begin{array}{c}\text { Specially protected natural areas } \\
\text { (PAs) (reserves, national and } \\
\text { natural parks, etc.) }\end{array}$ & $\begin{array}{c}\text { Implementation of ecological links } \\
\text { between key territories } \\
\text { (valleys of rivers, lakes, etc.) }\end{array}$ & $\begin{array}{c}\text { Protection of key and transit } \\
\text { territories from adverse external } \\
\text { influences (security zones) }\end{array}$ \\
\hline
\end{tabular}

Considering the "ecological framework" concept in the key to the territories functioning, it can be divided into natural and demo-economic. 
The natural framework is lines and zones system of special ecological responsibility, which includes large forest tracts, river valleys and lakes, while the demo-economic framework is industrial, commercial, business centers, residential areas and connecting transport arteries [5]. The creation of sites' organized network with different nature management regimes will make it possible to achieve a balance between the natural and demo-economic frameworks, thereby weakening the anthropogenic impact on the ecological framework and will develop the humane territories organization.

At this stage it is worth mentioning the notion of "urban area organization", which is the provision of living optimal standard and the efficiency of the territories use, achieved by securing a certain functional purpose, which, in aggregate, constitutes a single planning framework of the city. The establishment of the territory's designation and its functional filling is indicated by the strategic document "Master plan". The following Novosibirsk functional zoning was established: residential development zones, public and business zones, industrial zones, recreational area zones, urban forest areas, recreational areas, squares and parks, areas of medical facilities. According to the Land Code of the Russian Federation, the land for recreational purposes includes the land plots with hotels, campsites, objects of physical culture and sports, etc. [1].

City recreational areas include SPNA (specially protected natural areas), city parks of culture and resting, boulevards, squares and embankments, resting and landscape areas.

Recreational areas form a microclimate; contribute to the conservation of biodiversity gene pool, the most valuable ecosystems, and terrestrial and soil fauna. They participate in the regulation of the wind regime, the stabilization of water quality and the normal hydrological regime, perform an erosion-stabilizing function, a reference, training and educational, and provide a comfortable stay and so on [4].

\section{Results}

As a result of the work with the master plan and graphoanalytical method, schemes for Novosibirsk recreational zones location were compiled (Table 2).

The study showed that the recreational areas occupy about $20 \%$ of the city's territory. It is worth noting the placement of green areas (parks and squares).

Table 2. The scheme of the location of recreational zones in the city structure, Novosibirsk

\begin{tabular}{|c|c|}
\hline & Novosibirsk \\
\hline The area of the land & $502,1 \mathrm{~m}^{2}$ \\
General view of the city & \\
\hline
\end{tabular}




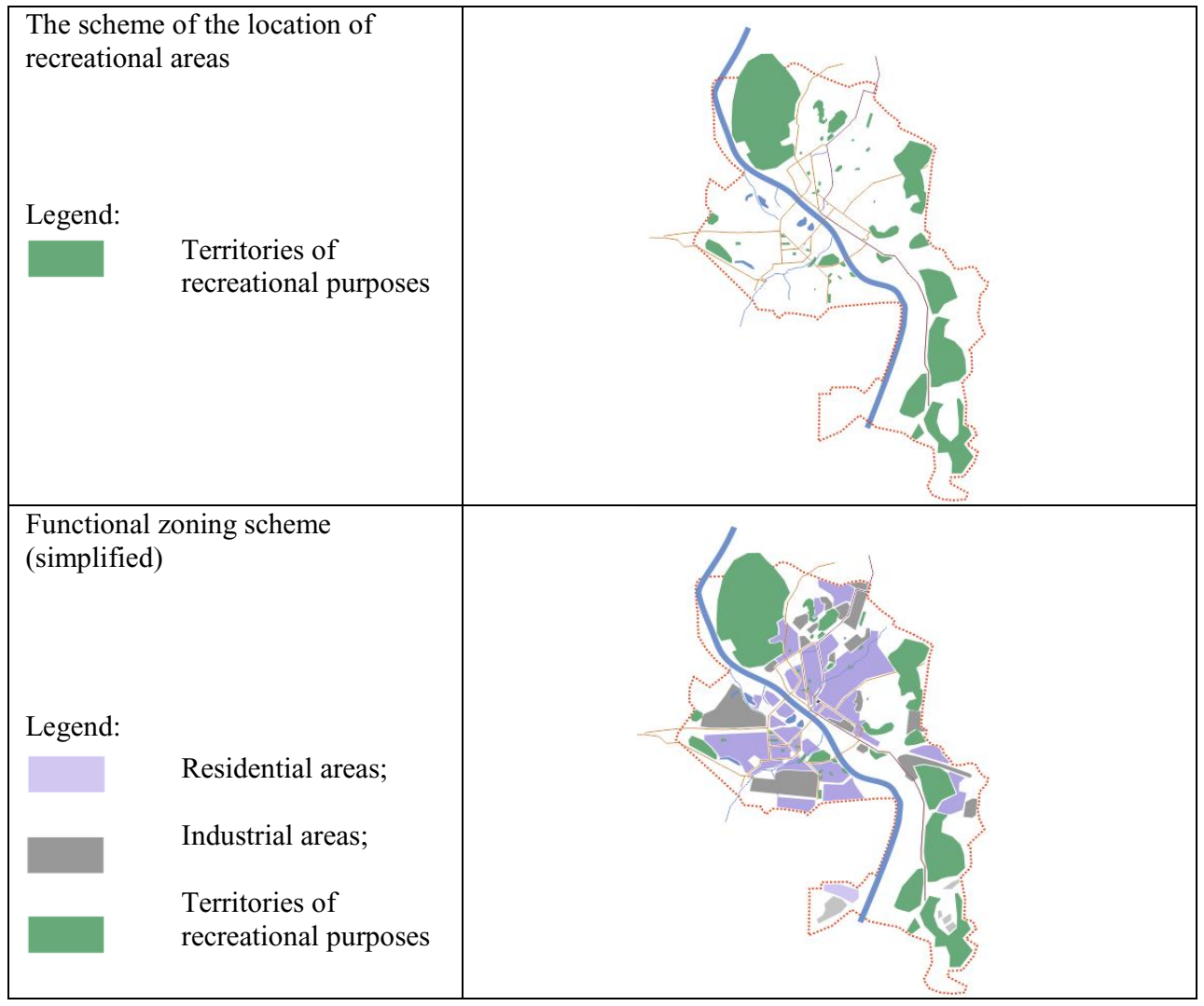

There are 57 parks and squares in the city body. However their gardening area is not as large as their number. The largest and the oldest Park of Culture and Leisure are Central Park (9.4 hectares).

One of the large greenery complexes, located in the north-east of the city, is the Zaeltsovsky Park of Culture and Rest tandem, the Dendropark and the Zoo in the Zaeltsovsky forest borough. The distinctive feature and attractiveness of the complex is the widest possible opportunities for providing recreational services that allow opportunities to choose the personal way of resting, including the placement for children's camps.

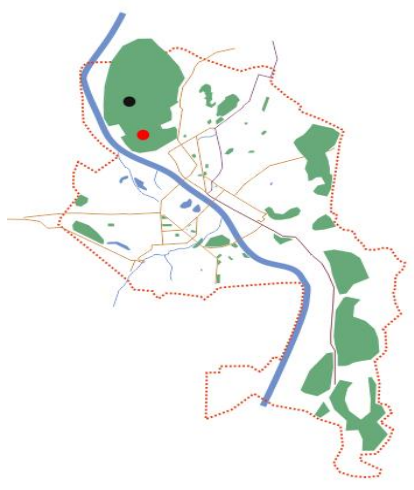

Active DALE

Abandoned DALE

Fig 3. Map-scheme of the reserve recreational areas location in Novosibirsk. 
There are 2 children's camps on the territory of the Forest borough (Figure 3), however, one of them is abandoned. The extinction of the camp functioning came along with a change in the country economic and political system, in connection with, the buildings and objects turned out to be mothballed. The buildings were dismantled; further work was not carried out on the former camp territory in the early 2010 's.

The function degradation and the change in the demand structure of the territory use comes with the appearance of the society new needs, while the comprehension and development of already existing object activity becomes of little interest.

\section{Discussion}

The study found the recreational zones extinction in the cities structure can lead to a number of negative consequences for the population: a decrease in the quality of citizens' life, an increase in the diseases number, including respiratory tract, a decrease in the attractiveness and ergonomics of the urban area, as well as environmental degradation in whole. In this connection, the theory of preservation and reconstruction of the recreational territories majority is put forward, namely:

a) organization of a mechanism for the reserve areas re-functioning or the revival of the recreational areas former function;

b) creation of a continuous relationship between urban existing massifs and suburban green areas;

c) creation of special protective strips for urban territories uniform differentiation

\section{Conclusion}

Sustainable development of recreational areas can be planned in a case of a hierarchy in the self-organizing system creation, which depends both on anthropogenic influence and on the established natural structure.

A new structure of skeletons is formed if the role of the city is not measured with the size of its nearest territorial influence zone and with the volume of its production capacities, where the level of the city is largely determined by its ability to provide developed infrastructure, effectively include different types of activities in its economic space [3].

The city is a living organism with the process of its permanent reformatting and its structure deformation. As a result, involuntary mixing and condensation of functional saturation takes place, the city life activity, natural and socio-economic ecosystem is changing.

\section{References}

1. The Land Code of the Russian Federation (as amended on July 3, 2016), Collected Legislation of the Russian Federation, 98 (2017)

2. A.R. Kataeva, Formation of the ecological framework as a principle of urban environment sustainable development, News of high schools, Architecton, 38 (2012)

3. V.I. Korobko, Urban economy, The publishing center "Academy", 160 (2008)

4. N.A. Narbut, InterCardo / InterGIS, 1 (21), 119-123 (2015)

5. A.I. Treyvish, The territory development and the territorial concentration of productive forces: the relationship and role in the process of intensification, IG AN SSSR, Moscow, 56 - 70 (1987) 